\title{
Validation of a web-based dietary questionnaire designed for the DASH (Dietary Approaches to Stop Hypertension) diet: the DASH Online Questionnaire
}

\author{
Caroline M Apovian ${ }^{1,2}$, Megan C Murphy ${ }^{3, *}$, Diana Cullum-Dugan ${ }^{2}+$, Pao-Hwa Lin ${ }^{4}$, \\ Kathryn Meyers Gilbert ${ }^{3}$, Gerald Coffman ${ }^{5}$, Mark Jenkins ${ }^{6}$, Peter Bakun ${ }^{7}$, Katherine L \\ Tucker $^{7}$ and Thomas Joseph Moore ${ }^{8}$ \\ ${ }^{1}$ Boston University School of Medicine, Boston, MA, USA: ${ }^{2}$ Center for Nutrition and Weight Management, \\ Boston Medical Center, Boston, MA, USA: ${ }^{3}$ DASH for Health, 715 Albany Street, Evans 7, Boston, MA 02118 , \\ USA: ${ }^{4}$ Department of Medicine, Duke University Medical Center, Durham, NC, USA: ${ }^{5}$ Data Coordinating \\ Center, Boston University School of Public Health, Boston University Medical Campus, Boston, MA, USA: ${ }^{6}$ DASH \\ for Health, Vineyard Haven, MA, USA: ${ }^{7}$ Jean Mayer USDA Human Nutrition Research Center on Aging, Tufts \\ University, Boston, MA, USA: ${ }^{8}$ Office of Clinical Research, Boston University Medical Center, Boston, MA, USA
}

Submitted 12 March 2009: Accepted 27 September 2009: First published online 16 November 2009

\begin{abstract}
Objective: With the upsurge in online dietary modification programmes, online dietary assessment tools are needed to capture food intake. Although the DASH (Dietary Approaches to Stop Hypertension) diet is recommended by the US Department of Agriculture, there are no online instruments that capture DASH food servings. Our objective was to assess the validity of a new, short, online dietary questionnaire developed to capture intake of DASH food servings. The DASH Online Questionnaire (OLQ) was validated against the well-known Block Food Frequency Questionnaire (FFQ).

Design: This was a cross-sectional validation of the DASH OLQ, which contained eleven food groups (breakfast cereals; dairy; drinks; fats and oils; fruits; grains and snacks; meat, fish and poultry; mixed dishes; sweets; vegetables; and nuts, seeds and legumes). Each subject completed a DASH OLQ once weekly for four weeks and one 98.2 Block FFQ (110 questions) between weeks 2 and 4. DASH OLQ were averaged and then compared with the Block FFQ for nutrient intakes as well as intakes of DASH food groups.

Setting: Boston University Medical Center, Boston, Massachusetts.

Subjects: One hundred and ninety-one faculty and staff at Boston University Medical Center aged 20-70 years.

Results: There were significant positive correlations between the Block FFQ and the DASH OLQ for all food groups ranging from $r=0 \cdot 8$ for the nuts/seeds/legumes category to $r=0.3$ for vegetables and mixed dishes. A comparison of nutrient intakes found strong positive correlations in all nutrient categories. Of particular interest in the DASH diet and the web-based nutrition and physical activity programme were total fat $(r=0 \cdot 62)$, total carbohydrate $(r=0 \cdot 67)$, total K $(r=0 \cdot 68)$, total $\mathrm{Ca}(r=0 \cdot 69)$, total vitamin $\mathrm{C}(r=0 \cdot 60)$ and total energy intake $(r=0 \cdot 68)$.

Conclusions: The DASH OLQ captures food and nutrient intake well in relation to the more established Block FFQ.
\end{abstract}

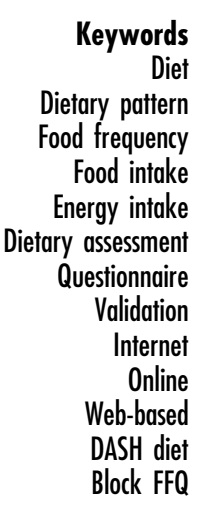

There is an ongoing need to improve eating habits and offer preventive approaches for weight management in the $\mathrm{USA}^{(1-3)}$. The Internet offers great possibilities in this regard because information can be sent to a very large audience at a relatively low cost. Our nutrition research group, made up of physicians, dietitians and nutritionists from Boston

\footnotetext{
$\dagger$ Present affiliation: DASH for Health, Newton, MA, USA.
}

University Medical Center, Duke University Medical Center and the USDA Human Nutrition Center on Aging at Tufts University, has developed an online lifestyle modification programme based on the DASH (Dietary Approaches to Stop Hypertension) diet. The DASH Online Questionnaire (OLQ) was created to capture food intake and provide realtime feedback in the form of progress reports to participants enrolled in the DASHforHealth.com programme. 
The aim of the DASHforHealth.com programme is to provide easily accessible nutrition education for those seeking to improve their health and/or combat weight issues via the Internet. Data collected using the DASH OLQ showed that participants significantly increased their daily fruit and vegetable consumption after one year in the DASHforHealth.com online programme ${ }^{(4)}$. The DASHforHealth.com programme is currently being offered to several US corporations as an employee wellness programme, as well as to the general public for individual subscription. We chose the DASH diet as the focus of our web-based educational programme because of its proven benefits in the areas of blood pressure reduction, cholesterol reduction, improvement of bone density, effectiveness when combined in a weight-loss programme, and protection against heart disease and stroke ${ }^{(5-12)}$. The DASH diet is a diet rich in fruits, vegetables, whole grains and low-fat dairy products, and reduced in meats, sugary sweets and fat (for example, for an energy intake of $8368 \mathrm{~kJ}$ (2000 kcal) the DASH diet would recommend the following servings: 4 fruit, 4 vegetable, 2.5 low-fat dairy, 7 grain, 1.5 meat/fish/poultry, 0.5 nuts/seeds/legumes, 2 added fats and 0.5 sweets $)^{(13)}$. The DASH diet is part of the therapeutic lifestyle changes recommended for patients with hypertension by the Joint National Committee on Prevention, Detection, Evaluation, and Treatment of High Blood Pressure ${ }^{(14)}$. In addition, the DASH diet is recommended by the US Department of Agriculture (USDA) as a healthy eating pattern for all American adults ${ }^{(15)}$.

Previous reports have demonstrated that subjects who keep track of what they eat (self-monitoring) adhere better to a dietary modification plan ${ }^{(16)}$. However, existing methods of assessment tend to be cumbersome, discouraging compliance ${ }^{(17-19)}$. Therefore, we created a selfmonitoring tool designed to capture changes made in dietary behaviours as a result of the DASHforHealth.com online programme with the caveat that the tool be quick and easy to use. This tool was designed as a brief online questionnaire that captured the consumption of servings in the various food groups, as recommended in the DASH diet. In order to test the utility of this tool we validated this online questionnaire (the DASH OLQ) $v$. the Block 98.2 Food Frequency Questionnaire (FFQ) as our gold standard. The present paper describes the design and the results of this validation study.

\section{Subjects and methods}

\section{Subjects and recruitment}

Subjects were recruited by mass email sent to 4000 faculty and staff of Boston University Medical Center. A total of 235 individuals enrolled in under $3 \mathrm{~h}$ using an online process. Among these individuals, 191 completed the criteria for inclusion in the study: completion of four DASH OLQ and one Block FFQ.

\section{Study design}

Subjects completed a demographic questionnaire which included questions about age, gender, race and educational level. They consumed their usual, free-choice diets throughout the study period. Study subjects were asked to complete the DASH OLQ once each week for four weeks including one weekend day and to complete the Block 98.2 FFQ once, between weeks 2 and 4 of the study period. Reminder emails were sent to study participants with a link to the online questionnaire. Subjects logged on to the online questionnaire to enter their food items. Subjects were also encouraged to email any questions to the study coordinator. Results of the four DASH OLQ were averaged and then compared with the Block FFQ. Comparison across instruments was conducted both at the nutrient and food group levels. Online informed consent was obtained from subjects at the time of recruitment. The Institutional Review Board at Boston University Medical Center approved the study.

\section{Development of the DASH Online Questionnaire}

The DASH OLQ was developed through collaborative efforts of a team of nutritionists and clinical researchers at Boston University School of Medicine, the USDA Human Nutrition Research Center on Aging at Tufts University and Duke University Medical Center. The goal of this team was to design a relatively simple dietary data collection and self-monitoring tool. It was created to be a self-administered assessment of dietary intakes for those enrolled in a web-based nutrition and physical activity education programme (DASHforHealth.com). Unlike traditional FFQ, the DASH OLQ requires individuals to recall intakes over the previous $24 \mathrm{~h}$ only, based upon the concept of a $24 \mathrm{~h}$ dietary recall. Commonly eaten foods are grouped into eleven categories with additional questions asked to address $\mathrm{Na}$ and fat intake (Fig. 1). The programming of the DASH OLQ reassembled the eleven food categories into the eight DASH food groups based on ingredients. For example, the DASH OLQ has a category for drinks. From the drink category, 100\% fruit juice would be analysed as a fruit serving ( $6 \mathrm{oz}$ equals one serving) whereas sugar-sweetened beverages count as a serving of sweets (6 oz equals one serving). For the validation study, single-day food intake was captured at four time points and averaged in order to assess general dietary patterns to be compared with the Block FFQ.

After its development the questionnaire was converted to HTML format with check boxes and entry fields for self-administration and was placed on a secure web server at Boston University's Data Coordinating Center. Informal testing for ease of use and understandability was done on a subset of ten people.

\section{Administration of the DASH Online Questionnaire} The DASH OLQ was self-administered at the location of choice by subjects once each week for four weeks. To complete the DASH OLQ, participants were asked to 


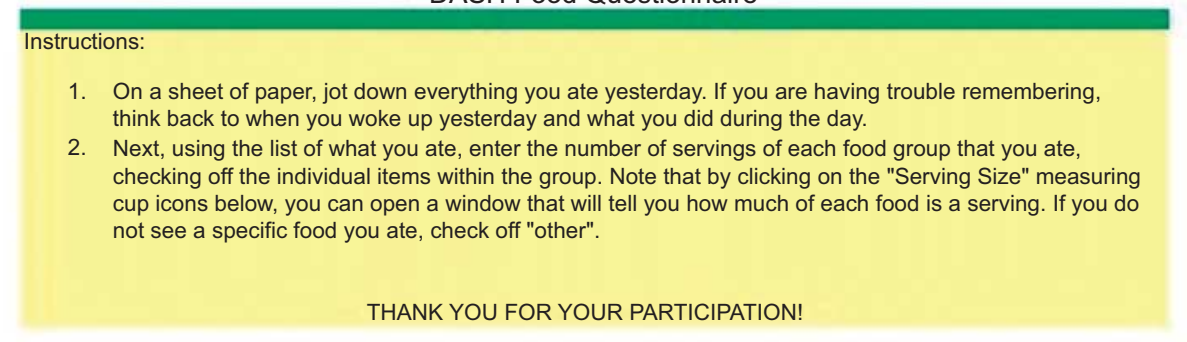

Questionnaire for Wednesday August 20, 2008

\begin{tabular}{|c|c|c|c|c|c|}
\hline \multirow{2}{*}{\multicolumn{2}{|c|}{$\frac{\text { Breakfast Cereals }}{\text { REFINED GRAIN CEREALS: }}$}} & \multirow[b]{3}{*}{$\Gamma$} & \multirow[b]{3}{*}{ corn flakes } & \multirow[b]{3}{*}{$\Gamma$} & Serving Size \\
\hline & & & & & Number of Servings \\
\hline$\Gamma$ & Product 19 & & & & Frosted Flakes \\
\hline 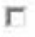 & Rice Krispies & $\Gamma$ & Corn Pops & $r$ & cream of wheat \\
\hline$r$ & Special K & $r$ & other & & \\
\hline \multicolumn{4}{|c|}{ WHOLE GRAIN CEREALS: } & & Number of Servings \\
\hline & Total & $\Gamma$ & raisin bran & $\Gamma$ & Cheerios \\
\hline$\Gamma$ & shredded wheat & $\Gamma$ & Wheaties & $r$ & oatmeal \\
\hline$r$ & other & & & & \\
\hline \multicolumn{4}{|c|}{ Grain Products/Snacks } & & Serving Size \\
\hline \multicolumn{2}{|c|}{ REFINED BREADS: } & & & & Number of Servings \\
\hline$r$ & white or light grain bread & $r$ & crackers & $\mathbf{r}$ & bagels \\
\hline$\Gamma$ & English muffins & $r$ & $\begin{array}{l}\text { rolls (including burger, hot dog } \\
\text { rolls) }\end{array}$ & $r$ & pancakes \\
\hline$\Gamma$ & waffles & $\Gamma$ & flour tortilla & $\Gamma$ & other \\
\hline \multicolumn{4}{|c|}{ WHOLE GRAIN BREADS: } & & Number of Servings \\
\hline$\Gamma$ & $100 \%$ whole wheat bread & $\Gamma$ & multi-grain bread & $\Gamma$ & whole grain crackers \\
\hline$\Gamma$ & whole grain bagels & $\Gamma$ & whole grain English muffins & $\Gamma$ & corn tortilla \\
\hline$\Gamma$ & other & & & & \\
\hline \multicolumn{5}{|c|}{$\begin{array}{l}\text { OTHER REFINED GRAIN PRODUCTS: (other than in pizza, lasagna and } \\
\text { macaroni and cheese) }\end{array}$} & Number of Servings \\
\hline$\Gamma$ & pasta & $\Gamma$ & white rice & $\Gamma$ & couscous \\
\hline$\Gamma$ & other & & & & \\
\hline \multicolumn{4}{|c|}{ OTHER WHOLE GRAIN PRODUCTS: } & & Number of Servings \\
\hline$\Gamma$ & whole grain pasta & $\Gamma$ & brown rice & $\Gamma$ & barley \\
\hline$\Gamma$ & bulgur & $\Gamma$ & other & & \\
\hline
\end{tabular}

Fig. 1 A sample of the DASH Online Questionnaire

recall and record all foods and approximate amounts eaten the day before on paper. They were then instructed to place a check next to the corresponding foods on the questionnaire and indicate the number of servings of each food consumed in designated entry fields. To aid in the estimation of serving sizes, clickable images were created for each food category as a reference; e.g. the fruit illustration showed 1 medium orange, 1/2 cup of sliced fruit or berries, 6 oz of $100 \%$ fruit juice and $1 / 4$ cup of dried fruit (Fig. 2). Food groups included: breakfast cereal; dairy; drinks; fats and oils; fruits; grain products and snacks; meat, fish and poultry; mixed dishes; sweets; vegetables; and nuts, seeds and legumes. These broad food group categories were further broken down into subcategories with individual food items that could be selected by clicking the appropriate check box (Fig. 1).

\section{Administration of the Block FFQ}

The paper-and-pencil 110-question Block 98.2 FFQ was self-administered at the location of the subjects' choice between weeks 2 and 4. The Block 98.2 FFQ measures food intake by asking participants to estimate how often they had eaten foods over the past year. Users were referred to a corresponding illustration of plates of different 


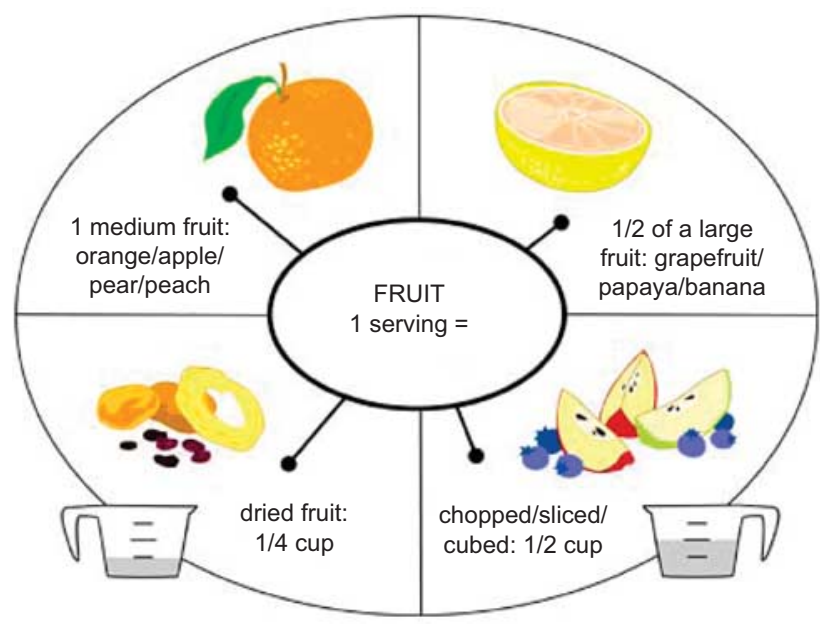

Fig. 2 Fruit illustration for estimating serving size when completing the DASH Online Questionnaire

sizes with differing amounts of food on them to aid in serving size estimation. Completed questionnaires were either mailed back to the research office or handdelivered to the research coordinator. Upon receipt, the Block FFQ was checked for completeness, and then sent to NutritionQuest (Berkeley, CA, USA) for data scanning and nutrient calculations. These results were returned to the USDA Human Nutrition Research Center on Aging at Tufts University for analysis. A total of 191 subjects completed the Block FFQ.

\section{Statistical methods}

The FFQ was scored through a scanning technique. Food frequency, nutrient and serving size data were obtained from the questionnaire through NutritionQuest (www.nutritionquest.com). Both the Block and DASH servings were converted to gram weights and compared using four different levels of adjustment. First, correlations were calculated with no adjustment. Second, deattentuated correlations were calculated using the formula suggested by Willett ${ }^{(20)}$. Intra/inter-individual variance ratios for the four days of reported DASH group intakes were calculated with the VARCOMP procedure in the SAS statistical software package version $9 \cdot 1 \cdot 3$ (SAS Institute, Cary, NC, USA) to control for day-to-day variability in intake. Third, an energy-adjusted correlation was done, and finally an energy-adjusted, deattentuated correlation was performed. Finally, agreement between the two data collection tools was calculated using kappa statistics.

\section{Comparison of foods by category}

To compare the DASH OLQ against the Block FFQ, gram weights of each DASH food group were averaged across all four completed questionnaires. Gram weights were then converted back into DASH servings. Food group analysis was done by calculating DASH serving sizes from
Table 1 Demographic characteristics of the study population: volunteers from faculty and staff of Boston University Medical Center (Boston, MA, USA), recruited by email

\begin{tabular}{lccc}
\hline & Mean or $\%$ & SD & Range \\
\hline Age (years) & $39 \cdot 9$ & $11 \cdot 4$ & $20-70$ \\
Height (m) & $1 \cdot 68$ & $0 \cdot 09$ & $1 \cdot 47-2 \cdot 03$ \\
Height (in) & $66 \cdot 3$ & $3 \cdot 6$ & $58-80$ \\
Weight (kg) & $69 \cdot 5$ & $16 \cdot 2$ & $43 \cdot 1-136 \cdot 1$ \\
Weight (lb) & $153 \cdot 2$ & $35 \cdot 8$ & $95-300$ \\
BMl (kg/m ${ }^{2}$ ) & $24 \cdot 4$ & $5 \cdot 5$ & $16 \cdot 0-51 \cdot 5$ \\
Race/ethnicity (\%) & & & \\
$\quad$ Non-Hispanic white & $80 \cdot 2$ & & \\
Non-Hispanic black & $2 \cdot 6$ & & \\
Hispanic white & $2 \cdot 6$ & & \\
Hispanic black & $2 \cdot 1$ & & \\
Asian & $10 \cdot 4$ & & \\
American Indian & 0.5 & & \\
Other & 1.6 & & \\
\hline
\end{tabular}

gram weights of Block foods and then summing these servings into each of the eleven DASH food groups. These entries were compared with the gram weights reported on the Block FFQ. Subgroups of breakfast cereals and mixed dishes were analysed individually because of the variability of these two items and also because it is difficult to estimate serving sizes from mixed dishes. Pearson correlation coefficients for the within-subject DASH OLQ $v$. Block FFQ for each DASH food group were computed.

\section{Comparison of nutrients}

Nutrient analysis was done by converting food intake reports from the OLQ from DASH servings to gram weights and then calculating nutrient intakes using a $100 \mathrm{~g}$ nutrient reference table, built using the USDA National Nutrient Database for Standard Reference version 18 (2001). Pearson correlation coefficients were then computed.

\section{Results}

The demographic characteristics of the participants are given in Table 1 . The study population was $75.5 \%$ female and $24.5 \%$ male, and the population was multi-ethnic. The study population was highly educated; fifty-nine respondents had some postgraduate work, fifty-nine completed college, twenty-four attended some college, six had a high school degree and one attended some high school. Three respondents did not report their level of education.

\section{Comparisons of the DASH Online Questionnaire and Block FFQ by food group}

Eleven DASH food groups were compared with the Block FFQ. Significant positive correlations between the Block FFQ and the DASH OLQ were found for all eleven DASH food groups. Correlations were as follows: breakfast 
Table 2 Mean intakes and Pearson's correlations between the DASH OLQ and the Block 98.2 FFQ for intakes of food by DASH food group: volunteers from faculty and staff of Boston University Medical Center (Boston, MA, USA), recruited by email ( $n$ 191)

\begin{tabular}{|c|c|c|c|c|c|c|c|c|}
\hline \multirow[b]{2}{*}{ Food group } & \multicolumn{4}{|c|}{ Mean intake (g) } & \multicolumn{4}{|c|}{ Correlation coefficients } \\
\hline & $\begin{array}{l}\text { DASH } \\
\text { OLQ }\end{array}$ & SD & $\begin{array}{c}\text { Block } \\
\text { FFQ }\end{array}$ & SD & $\begin{array}{l}\text { Unadjusted } \\
\text { correlation }\end{array}$ & $\begin{array}{c}\text { Unadjusted } \\
\text { deattenuated }\end{array}$ & $\begin{array}{l}\text { Energy- } \\
\text { adjusted }\end{array}$ & $\begin{array}{l}\text { Energy-adjusted } \\
\text { deattenuated }\end{array}$ \\
\hline Fruit & $271 \cdot 3$ & $214 \cdot 3$ & $300 \cdot 5$ & $228 \cdot 5$ & 0.61 & $0 \cdot 70$ & 0.56 & 0.64 \\
\hline Vegetables & $205 \cdot 1$ & $97 \cdot 0$ & $191 \cdot 7$ & $142 \cdot 9$ & 0.31 & $0 \cdot 41$ & 0.29 & 0.39 \\
\hline Grains & $130 \cdot 4$ & $59 \cdot 6$ & $159 \cdot 4$ & $90 \cdot 7$ & $0 \cdot 41$ & 0.53 & 0.33 & 0.42 \\
\hline Dairy & $219 \cdot 5$ & $162 \cdot 1$ & $265 \cdot 2$ & $202 \cdot 4$ & $0 \cdot 70$ & $0 \cdot 81$ & 0.66 & 0.77 \\
\hline Nuts, seeds and legumes & $47 \cdot 4$ & $75 \cdot 5$ & $28 \cdot 0$ & $36 \cdot 4$ & 0.80 & 0.93 & 0.79 & 0.92 \\
\hline Meat, fish and poultry & $100 \cdot 9$ & $67 \cdot 4$ & 83.6 & $52 \cdot 2$ & 0.49 & 0.59 & 0.45 & 0.54 \\
\hline Sweets & $42 \cdot 1$ & $36 \cdot 7$ & $32 \cdot 0$ & $25 \cdot 2$ & 0.51 & 0.71 & 0.43 & 0.59 \\
\hline Fats and oils & $13 \cdot 6$ & $10 \cdot 9$ & $30 \cdot 5$ & $23 \cdot 8$ & 0.34 & 0.46 & 0.31 & 0.42 \\
\hline Mixed dishes & $134 \cdot 5$ & $118 \cdot 6$ & $149 \cdot 4$ & $109 \cdot 0$ & $0 \cdot 32$ & 0.51 & 0.32 & 0.51 \\
\hline Breakfast cereal & $21 \cdot 2$ & $26 \cdot 6$ & $30 \cdot 8$ & $35 \cdot 5$ & $0 \cdot 67$ & 0.89 & 0.66 & 0.87 \\
\hline Drinks & $1478 \cdot 0$ & $669 \cdot 0$ & $1438 \cdot 0$ & $566 \cdot 0$ & 0.62 & 0.68 & 0.62 & 0.69 \\
\hline
\end{tabular}

DASH, Dietary Approaches to Stop Hypertension; OLQ, online questionnaire.

Table 3 Mean intakes and Pearson's correlations between the DASH OLQ and the Block 98.2 FFQ for energy and nutrient intakes: volunteers from faculty and staff of Boston University Medical Center (Boston, MA, USA), recruited by email $(n$ 191)

\begin{tabular}{|c|c|c|c|c|c|c|c|c|}
\hline & \multicolumn{4}{|c|}{ Mean intake $(\mathrm{g})$} & \multicolumn{4}{|c|}{ Correlation coefficients } \\
\hline & $\begin{array}{l}\text { DASH } \\
\text { OLQ }\end{array}$ & SD & $\begin{array}{l}\text { Block } \\
\text { FFQ }\end{array}$ & SD & $\begin{array}{l}\text { Unadjusted } \\
\text { correlation }\end{array}$ & $\begin{array}{c}\text { Unadjusted } \\
\text { deattenuated }\end{array}$ & $\begin{array}{l}\text { Energy- } \\
\text { adjusted }\end{array}$ & $\begin{array}{l}\text { Energy-adjusted } \\
\text { deattenuated }\end{array}$ \\
\hline Energy (kJ) & 6954 & 2050 & 6925 & 2397 & 0.68 & 0.77 & - & - \\
\hline Energy (kcal) & $1662 \cdot 0$ & $490 \cdot 0$ & $1655 \cdot 0$ & $573 \cdot 0$ & $0 \cdot 68$ & $0 \cdot 77$ & - & - \\
\hline Protein (g) & $72 \cdot 0$ & $24 \cdot 0$ & 61.6 & $23 \cdot 8$ & 0.56 & 0.66 & 0.35 & 0.42 \\
\hline Carbohydrate (g) & $204 \cdot 0$ & $61 \cdot 4$ & $203 \cdot 6$ & $72 \cdot 3$ & 0.67 & $0 \cdot 75$ & 0.51 & 0.57 \\
\hline Fat $(\mathrm{g})$ & $60 \cdot 8$ & $23 \cdot 7$ & $64 \cdot 2$ & $27 \cdot 8$ & 0.62 & 0.72 & 0.53 & 0.62 \\
\hline Saturated fat $(\mathrm{g})$ & $21 \cdot 4$ & 8.9 & $19 \cdot 1$ & $8 \cdot 6$ & $0 \cdot 60$ & 0.71 & 0.50 & 0.60 \\
\hline Vitamin A (RE) & $1068 \cdot 0$ & $788 \cdot 9$ & $1158 \cdot 0$ & $727 \cdot 1$ & 0.52 & 0.67 & 0.45 & 0.58 \\
\hline Vitamin E (TE) & $7 \cdot 1$ & $3 \cdot 3$ & $9 \cdot 3$ & 4.5 & 0.56 & $0 \cdot 70$ & 0.46 & 0.57 \\
\hline Vitamin C (mg) & $118 \cdot 7$ & $74 \cdot 4$ & $115 \cdot 8$ & $72 \cdot 1$ & $0 \cdot 60$ & 0.69 & 0.56 & 0.65 \\
\hline Vitamin $B_{6}(\mathrm{mg})$ & $1 \cdot 7$ & 0.6 & $1 \cdot 6$ & 0.7 & 0.62 & 0.74 & 0.52 & 0.62 \\
\hline Folate $(\mu \mathrm{g})$ & $342 \cdot 0$ & $129 \cdot 6$ & $360 \cdot 0$ & $148 \cdot 7$ & 0.67 & 0.77 & 0.62 & $0 \cdot 71$ \\
\hline $\mathrm{Fe}(\mathrm{mg})$ & $13 \cdot 1$ & $5 \cdot 0$ & $13 \cdot 1$ & $5 \cdot 7$ & 0.67 & $0 \cdot 76$ & 0.59 & 0.67 \\
\hline $\mathrm{Na}(\mathrm{mg})$ & $3071 \cdot 0$ & $938 \cdot 2$ & $2328 \cdot 0$ & $903 \cdot 1$ & 0.55 & $0 \cdot 66$ & 0.41 & 0.49 \\
\hline $\mathrm{Zn}(\mathrm{mg})$ & $9 \cdot 7$ & 3.9 & $9 \cdot 7$ & $4 \cdot 8$ & 0.44 & 0.55 & 0.25 & $0 \cdot 31$ \\
\hline $\mathrm{Ca}(\mathrm{mg})$ & $885 \cdot 6$ & 371.9 & $1189 \cdot 0$ & $389 \cdot 7$ & 0.59 & 0.73 & 0.49 & 0.60 \\
\hline$P(\mathrm{mg})$ & $1189 \cdot 0$ & $389 \cdot 7$ & $1071 \cdot 0$ & $416 \cdot 8$ & 0.69 & $0 \cdot 80$ & 0.60 & $0 \cdot 70$ \\
\hline $\mathrm{K}(\mathrm{mg})$ & $2581 \cdot 0$ & $834 \cdot 0$ & $2670 \cdot 0$ & $1032 \cdot 0$ & 0.68 & 0.78 & 0.62 & 0.71 \\
\hline Thiamin (mg) & $1 \cdot 3$ & 0.4 & $1 \cdot 3$ & 0.6 & 0.61 & 0.74 & 0.49 & 0.59 \\
\hline Riboflavin (mg) & 1.5 & 0.5 & $1 \cdot 6$ & 0.6 & 0.69 & 0.80 & 0.63 & 0.73 \\
\hline $\mathrm{Mg}(\mathrm{mg})$ & $303 \cdot 0$ & $119 \cdot 0$ & $270 \cdot 0$ & $108 \cdot 0$ & 0.69 & 0.76 & 0.66 & 0.74 \\
\hline Fibre $(\mathrm{g})$ & $16 \cdot 7$ & $7 \cdot 5$ & $15 \cdot 8$ & $7 \cdot 5$ & 0.67 & $0 \cdot 76$ & 0.63 & $0 \cdot 70$ \\
\hline Linoleic acid $(\mathrm{mg})$ & $10 \cdot 1$ & $4 \cdot 8$ & $15 \cdot 2$ & $7 \cdot 5$ & 0.58 & $0 \cdot 70$ & 0.48 & 0.59 \\
\hline Oleic acid (mg) & 21.9 & $9 \cdot 1$ & $24 \cdot 8$ & $11 \cdot 4$ & 0.58 & $0 \cdot 70$ & $0 \cdot 40$ & 0.48 \\
\hline Cholesterol (mg) & $151 \cdot 0$ & $71 \cdot 0$ & $167 \cdot 0$ & $75 \cdot 0$ & 0.46 & 0.56 & 0.36 & 0.44 \\
\hline Niacin $(\mathrm{mg})$ & $20 \cdot 1$ & $6 \cdot 8$ & $18 \cdot 3$ & $7 \cdot 5$ & 0.52 & 0.63 & 0.33 & 0.40 \\
\hline
\end{tabular}

DASH, Dietary Approaches to Stop Hypertension; OLQ, online questionnaire; RE, retinol equivalents; TE, $\alpha$-tocopherol equivalents.

All correlations were significant: $P<0.0001$.

cereals $(r=0 \cdot 67)$, drinks $(r=0 \cdot 62)$, fruit $(r=0 \cdot 61)$, nuts, seeds and legumes $(r=0 \cdot 80)$ and dairy $(r=0 \cdot 70)$. Lower, but still significant correlations were seen for meat, fish and poultry $(r=0 \cdot 49)$, vegetables $(r=0 \cdot 31)$, fats and oils $(r=0 \cdot 34)$, grains $(r=0 \cdot 41)$, mixed dishes $(r=0 \cdot 32)$ and sweets $(r=0 \cdot 51)$. Deattenuated correlations ranged from $r=0.41$ for vegetables to $r=0.93$ for nuts, seeds and legumes (Table 2). Mean intakes across instruments did not differ significantly for vegetables, drinks or mixed dish groups. However, significant differences were found for the remaining eight food groups.

\section{Comparisons of the DASH Online Questionnaire and Block FFQ by nutrients}

Comparison of the two assessment methods showed significant positive correlations for all nutrients ranging from $r=0.44$ for $\mathrm{Zn}$ to $r=0.69$ for $\mathrm{Mg}$, P and riboflavin. Deattenuated correlations were even stronger, ranging from $r=0.55$ for $\mathrm{Zn}$ to $r=0.80$ for riboflavin and P. Mean intakes across instruments did not differ significantly for energy, carbohydrate, vitamin A, vitamin $\mathrm{C}$, riboflavin, thiamin, vitamin $\mathrm{B}_{6}, \mathrm{Fe}, \mathrm{Zn}$ or $\mathrm{K}$ (Table 3), but were significantly higher for the Block FFQ $v$. the DASH OLQ for 
fat, vitamin $\mathrm{E}$ and foliate, and higher for the DASH OLQ $v$. the Block FFQ for protein, $\mathrm{Na}$ and $\mathrm{P}$.

Weighted kappa statistics were performed to determine the level of agreement the DASH OLQ had with the Block FFQ by energy level. A value of $0 \cdot 48$ (95\% CI 0.38, 0.57; $P<0 \cdot 0001)$ or 'moderate' agreement was observed.

\section{Discussion}

Overweight and obesity in the USA are at an all-time high, mainly due to unhealthy eating patterns as well as little physical activity. Unhealthy eating patterns and obesity are associated with co-morbidities such as hypertension, elevated lipids and type 2 diabetes. Solutions to the rising health-care burden include modification of dietary intake to reduce the costs associated with nutrition-related chronic disease. Research in dietary food patterns requires methods of capturing food intake. Although nutritional biological markers are the most accurate way to detect dietary consumption, they are expensive and impractical for the general public ${ }^{(21,22)}$. The low cost and simplicity of self-administered dietary recall questionnaires facilitates their use in large populations and is the primary method of dietary intake data collection in most epidemiological studies ${ }^{(23,24)}$. However, most FFQ are administered on paper and are thus cumbersome to administer and analyse.

The Internet presents a promising mode of disseminating nutrition education on the population level, and an online dietary intake assessment tool would conveniently track change in lifestyle for nutrition research. FFQ are used to measure average long-term dietary patterns rather than to provide an exact estimate of short-term intake ${ }^{(20,25)}$. The DASH OLQ was designed to assess both short-term and longer-term changes in food intake by tracking food intake for multiple $24 \mathrm{~h}$ periods and averaging them. We theorize that those averages can be compared over time to determine dietary intake change, in addition to capturing short-term improvements to dietary intake, and view this topic as a potential for future research. The DASH OLQ can be administered more frequently than a longer questionnaire because it is less timeconsuming to complete. Thus, the DASH OLQ has the potential to be used in a large population repeatedly with relatively low cost for administration and analysis.

We found that repeated use (four days in this case) of the DASH OLQ correlates well with the Block FFQ and is therefore a useful estimate of food intake in those who are attempting to follow the DASH diet. The energyadjusted and deattenuated correlations for nutrients in our study ranged from $0 \cdot 31(\mathrm{Zn})$ to $0.74(\mathrm{Mg})$. On average the correlation for these nutrients was approximately $0 \cdot 60$. Our results are comparable to those reported by similar studies that used the Block $98.2 \mathrm{FFQ}^{(26,27)}$. The DASH OLQ correlated best with the Block FFQ for breakfast cereals, drinks, fruit, nuts/seeds/legumes, meat/ fish/poultry, grains, dairy and sweets, and less well for fats/oils, vegetables and mixed dishes. Owing to day-today variation in specific food group intakes, there are inherent limitations in the comparison of four days of intake to the 'usual' assessment by the FFQ, which has respondents estimate their intake over the previous year. Therefore, it is likely that correlations may improve with tracking of more days. Deattenuated correlations, controlling for day-to-day variation, support this notion. It is interesting to note that adjusting for energy did not improve correlations, but rather weakened most. This observation is not unique to this validation study, however ${ }^{(28)}$. Our belief is that because both the Block FFQ and the DASH OLQ included pre-existing portion sizes in the questionnaires, adjustment for energy intake had less of an effect.

An additional limitation to the current study is the use of a highly educated sample population, and thus the study lacks generalizability to populations of lower socioeconomic status with limited access to the Internet. Further research is warranted to address whether or not a self-administered online questionnaire such as the DASH OLQ is effective and understandable to users with a variety of different backgrounds and educational levels.

The DASH (Dietary Approaches to Stop Hypertension) diet has been clinically shown to lower blood pressure, cholesterol and homocysteine concentrations, and may reduce the risk of heart disease, stroke and osteoporosis, and increase antioxidant concentrations in the body, and improve mood and quality of life $\mathrm{e}^{(5,8,10,12,29)}$. The DASH diet is low in saturated fat, total fat and cholesterol, has a moderate protein intake, and contains more $\mathrm{Ca}, \mathrm{K}, \mathrm{Mg}$ and fibre than does the average American diet. The results of the DASH trials have proved that such a diet would be beneficial not only for people with high blood pressure, those with pre-hypertension or a family history of high blood pressure, but also for those interested in reducing their risk of heart disease, stroke, osteoporosis and cancer risk, losing weight, and for those with an interest in feeling better, both mentally and physically ${ }^{(4,7,8,9,11,12)}$. Because of all of these factors the DASH diet is an ideal eating pattern to recommend to the entire American population. Until recently, information about the DASH diet was available only in written form. Our team has created an online programme based on the DASH diet that could be offered to the entire population, and uses the DASH OLQ as a method of assessing adherence to the DASH diet as a result of this online programme; however, the DASH OLQ can also be used outside the DASH for Health online programme. For the purposes of the present validation the DASH OLQ was administered independent of the DASH for Health online programme. While this tool can be used outside the DASH for Health programme, it is not currently. The DASH diet is now recommended by the USDA along with the Food Guide Pyramid as a healthy way for all Americans to eat. 
Making this tool more widely available would provide an important evaluation tool both to the public and to researchers.

In summary, our DASH OLQ correlated well with the established Block 98.2 FFQ across all micronutrients and DASH food groups. The Internet offers an important medium for offering an online dietary modification programme such as the DASHforHealth.com online programme and the DASH diet is an eating pattern that would benefit the majority of Americans. In the present study we have shown that the DASH OLQ is an important assessment tool for measuring adherence to the DASH diet.

\section{Summary}

The DASH OLQ was created to capture absolute intake of DASH servings of foods after exposure to a web-based nutrition and physical activity programme based on the DASH diet. For an Internet-based nutrition and physical activity programme to reliably receive feedback from those who use the site, a recall-based questionnaire must be accurate yet easy to use and relatively short compared with the typical FFQ, which can take 20-45 min to complete. In the present study, the validity of the DASH OLQ was evaluated by comparison with the Block FFQ. The average of four DASH OLQ was found to correlate well with the Block 98.2 FFQ and can be utilized as a quick measure to capture adherence to the DASH diet. This DASH OLQ may also be useful as a learning tool in employee or school settings, as well as for assessing adherence to the DASH diet in clinical practice and future research.

\section{Acknowledgements}

Sources of funding: The development of the online DASH dietary questionnaire was supported by a grant form the National Heart, Lung, and Blood Institute (3 01 HL5715604S2). Conflict of interest declaration: T.J.M. is Chairman of e-Havior Change, LLC which owns the copyright to the DASH for Health programme. C.M.A., M.C.M., D.C.-D., M.J., K.M.G., P.-H.L. and G.C. have received some salary support from e-Havior Change, LLC. Authors' contributions: C.M.A., M.C.M., D.C.-D., P.-H.L. and T.J.M. collaborated on the development and testing of the DASH OLQ, with collaboration on design from K.L.T. M.C.M. collected the data analysed for the purposes of this manuscript. G.C. and P.B. performed the analysis of the data for this manuscript with oversight by K.L.T. C.M.A., M.C.M., D.C.-D., K.M.G., M.J. and T.J.M. collaborated on writing and editing of this manuscript, with consultation from K.L.T.

\section{References}

1. Centers for Disease Control and Prevention (2006) Behavioral Risk Factor Surveillance System Survey Data. Atlanta, GA: US Department of Health and Human Services, CDC.
2. Mokdad AH, Ford ES, Bowman BA et al. (2003) Prevalence of obesity, diabetes, and obesity-related health risk factors, 2001. JAMA 289, 76-79.

3. Mokdad AH, Bowman BA, Ford ES et al. (2001) The continuing epidemics of obesity and diabetes in the United States. JAMA 286, 1519-1522.

4. Moore TJ, Alsabeeh N, Apovian C et al. (2008) Weight, blood pressure, and dietary benefits after 12 months of a web-based nutrition education program (DASH for Health): longitudinal observational study. J Med Internet Res $\mathbf{1 0}$, issue 4, e52.

5. Appel LJ, Moore TJ, Obarzanek E et al. (1997) A clinical trial of the effects of dietary patterns on blood pressure. DASH Collaborative Research Group. N Engl J Med 336, $1117-1124$.

6. Sacks FM, Svetkey LP \& Vollmer WM (2001) Effects on blood pressure of reduced dietary sodium and the Dietary Approaches to Stop Hypertension (DASH) diet. DASH-Sodium Collaborative Research Group. N Engl J Med 344, 3-10.

7. Folsom AR, Parker ED \& Harnack LJ (2007) Degree of concordance with DASH diet guidelines and incidence of hypertension and fatal cardiovascular disease. $\mathrm{Am} \mathrm{J}$ Hypertens 20, 225-232.

8. Elmer PJ, Obarzanek E, Vollmer WM et al. (2006) PREMIER Collaborative Research Group. Effects of comprehensive lifestyle modification on diet, weight, physical fitness, and blood pressure control: 18-month results of a randomized trial. Ann Intern Med 144, 485-495.

9. Obarzanek E, Sacks FM \& Vollmer WM (2001) Effects on blood lipids of a blood pressure-lowering diet: the Dietary Approaches to Stop Hypertension (DASH) Trial. Am J Clin Nutr 74, 1-2.

10. Lopes HF, Martin KL, Nashar K et al. (2003) DASH diet lowers blood pressure and lipid-induced oxidative stress in obesity. Hypertension 41, 422-430.

11. Fung TT, Chiuve SE, McCullough ML et al. (2008) Adherence to a DASH-style diet and risk of coronary heart disease and stroke in women. Arch Intern Med 168, 713-720.

12. Lin PH, Ginty F, Appel LJ et al. (2003) The DASH diet and sodium reduction improve markers of bone turnover and calcium metabolism in adults. J Nutr 133, 3130-3136.

13. Moore TJ (2001) The DASH Diet for Hypertension: Lower your Blood Pressure in 14 days. New York: Simon \& Schuster, Inc.

14. Chobanian AV, Bakris GL, Black HR et al. \& National High Blood Pressure Education Program Coordinating Committee (2003) Seventh report of the Joint National Committee on Prevention, Detection, Evaluation, and Treatment of High Blood Pressure. JNC 7-complete version. Hypertension 42, 1206-1252.

15. US Department of Health and Human Services \& US Department of Agriculture (2005) Dietary Guidelines for Americans, 2005, 6th ed. Washington, DC: US Government Printing Office.

16. Wing RR \& Hill JO (2005) Successful weight loss maintenance. Annu Rev Nutr 82, Suppl. 1, 222S-225S.

17. Kushi LH (1994) Gaps in epidemiologic research methods: design considerations for studies that use food-frequency questionnaires. Am J Clin Nutr 59, Suppl. 1, 180S-184S.

18. Block G (1989) Human dietary assessment: methods and issues. Prev Med 18, 653-660.

19. Blanton CA, Moshfegh AJ, Baer DJ et al. (2006) The USDA automated multiple-pass method accurately estimates group total energy and nutrient intake. $J$ Nutr 136, 2594-2599.

20. Willett W (1990) Nutritional Epidemiology, 2nd ed. New York: Oxford University Press.

21. Potischman N \& Freudenheim JL (2003) Biomarkers of nutritional exposure and nutritional status: an overview. J Nutr 133, Suppl. 3, 873S-874S. 
22. Bingham SA, Gill C, Welch A et al. (1997) Validation of dietary assessment methods in the UK arm of EPIC using weighed records, and 24-hour urinary nitrogen and potassium and serum vitamin $\mathrm{C}$ and carotenoids as biomarkers. Int J Epidemiol 26, Suppl. 1, S137-S151.

23. Mellen PB, Gao SK, Vitolins MZ et al. (2008) Deteriorating dietary habits among adults with hypertension: DASH dietary accordance, NHANES 1988-1994 and 1999-2004. Arch Intern Med 168, 308-314.

24. Buzzard IM, Faucett CL, Jeffery RW et al. (1996) Monitoring dietary change in a low-fat diet intervention study: advantages of using 24-hour dietary recalls vs food records. J Am Diet Assoc 96, 574-579.

25. Rimm EB, Giovannucci EL, Stampfer MJ et al. (1992) Reproducibility and validity of an expanded self-administered semiquantitative food frequency questionnaire among male health professionals. Am J Epidemiol 135 1114-1126.

26. Kumanyika SK, Mauger D, Mitchell DC et al. (2003) Relative validity of food frequency questionnaire nutrient estimates in the Black Women's Health Study. Ann Epidemiol 13, 111-118.

27. Boucher B, Cotterchio M, Kreiger N et al. (2006) Validity and reliability of the Block98 food-frequency questionnaire in a sample of Canadian women. Public Health Nutr 9, 84-93.

28. Block G, Wakimoto P, Jensen C et al. (2006) Validation of a food frequency questionnaire for Hispanics. Prev Chronic Dis 3 , A77.

29. Elmer PJ, Obarzanek E, Vollmer WM et al. (2006) Effects of comprehensive lifestyle modification on diet, weight, physical fitness, and blood pressure control: 18-month results of a randomized trial. Ann Intern Med 144, 485-495. 